\title{
Comparison of molded pulps from rice straw, pineapple leaf and banana stem pulps
}

\author{
Phattharasaya Rattanawongkun ${ }^{\mathrm{a}}$, Nutchanad Kunfong ${ }^{\mathrm{a}}$, Supattra Klayya ${ }^{\mathrm{a}}$, Thawan Chotimarnon ${ }^{\mathrm{a}}$, \\ Sitthi Duangphet $^{\mathrm{a}, \mathrm{b}}$, Nattaya Tawichai ${ }^{\mathrm{a}, \mathrm{b}}$, Uraiwan Intatha ${ }^{\mathrm{a}, \mathrm{b}}$, Nattakan Soykeabkaew ${ }^{\mathrm{a}, \mathrm{b}, *}$ \\ a School of Science, Mae Fah Luang University, Chiang Rai 57100 Thailand \\ b Center of Innovative Materials for Sustainability (iMatS), School of Science, Mae Fah Luang University, \\ Chiang Rai 57100 Thailand
}

*Corresponding author, e-mail: nattakan@mfu.ac.th

Received 16 Oct 2019

Accepted 6 Mar 2020

\begin{abstract}
Molded pulp is an eco-friendly packaging product popularly chosen nowadays. It is mostly used to replace plastic containers such as polypropylene (PP), polystyrene (PS) and polyethylene (PE). Besides, the non-wood pulps from agricultural crops and residues have been increasingly studied as alternative materials in pulp production. Therefore, this study aimed to investigate the possibility of utilizing rice straw $(R)$, pineapple leaf $(P)$ and banana stem (B) as raw materials to prepare pulps by using a soda-anthraquinone (AQ) pulping process. The pulping was carried out with $4-7 \%$ sodium hydroxide solution and $0.1 \%$ AQ, a liquid-solid ratio of 10:1, and pulping time of 15-30 min at $98 \pm 2{ }^{\circ} \mathrm{C}$. Next, the obtained pulps unscreened (u-) were sieved into screened (s-) portions, and the molded sheets from both u- and s-portions were formed using compression molding technique under pressure of $0.6 \mathrm{MPa}$ at $130{ }^{\circ} \mathrm{C}$ for $5 \mathrm{~min}$. The molded sheets from R pulp showed higher tensile strength and tensile index (62 MPa and $63.28 \mathrm{Nm} / \mathrm{g}$, respectively) when compared to the sheets from P and B pulps. From SEM images, the cross-sections of the R pulp sheets revealed less voids between fiber layers and, hence, better fiber-packing and bonding. Based on their mechanical properties compared to commercial molded pulp products, it suggested that these agricultural residues and their pulps can be considered promising alternative sources for pulp and molded pulp production.
\end{abstract}

KEYWORDS: molded pulp, rice straw, pineapple leaf, banana stem, soda-AQ pulping

\section{INTRODUCTION}

Molded pulp is an alternative material popularly used as containers, trays and other packaging these days [1]. For pulp manufacturing, the raw materials can be divided into 3 main types: wood, non-wood and recycled pulp [2]. Wood resources from both softwood and hardwood are typically the major raw materials for pulp and paper production. However, a limitation of wood plant is its long cultivation period. An insufficient supply leads to deforestation problem in some countries. This has influenced an increasing attention to non-wood resources [3, 4]. In agricultural countries, abundant sources of nonwoods can be obtained from agricultural wastes. Many of them are considered suitable for pulp production due to their high cellulose content, low lignin content, and desirable mechanical properties [5-7], for example, oil palm, sugarcane, rice straw, banana stem, bamboo, corn stalk as well as pineapple leaf [8]. Particularly, pineapple leaf and banana stem contain relatively high cellulose content (65-82\%). On the other hand, rice straw pulp shows the prominent tensile properties when compared to other pulps $[7,8]$. Basically, non-wood raw materials require a simple chemical treatment for pulping such as a soda process and the alkali charge which can be lower than in the wood pulping [4]. It has also been reported that the non-wood resources showed a higher production capacity and pulp yield than the wood resources [9-11]. For bast fibers, the soda-anthraquinone (AQ) pulping was found to provide good strength and high yield [12], and this process was also suitable for agricultural crops and their wastes pulping [13]. This research was aimed to investigate the possibility of using rice straw $(R)$, pineapple leaf $(P)$ and banana stem (B) as alternative resources in the molded pulp manufacturing. The soda-AQ was used to prepare the pulps from $\mathrm{R}, \mathrm{P}$ and $\mathrm{B}$ raw materials. The molded sheets from each pulp were formed by using the compression molding technique. The physical properties, morphology and tensile properties of the resulting molded sheets were characterized and also 


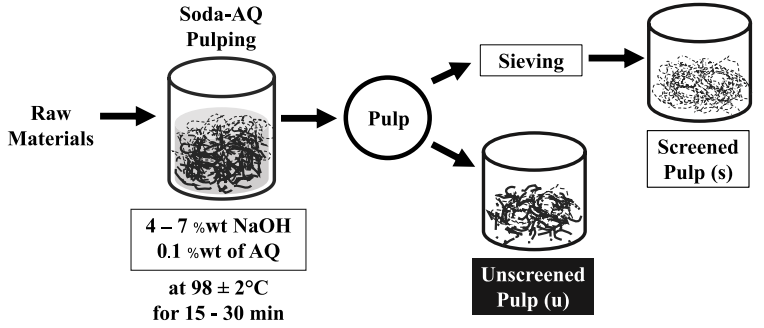

Fig. 1 Preparation of rice straw, pineapple leaf and banana stem pulps by using soda-AQ pulping process.

compared to commercial molded pulp products.

\section{MATERIALS AND METHODS}

\section{Materials}

All of the raw materials were collected from local areas in Chiang Rai, Thailand. Rice straw (R) residue was harvested from the rice field area in Mae Lao subdistrict. It was pulverized (Nimut Engineering Co., Ltd.), dried in a hot-air oven, and then stored in a vacuum bag. Nanglae pineapple leaf (P) was collected from the cultivation area in Nanglae subdistrict. Banana stem (B) waste was provided by the Botanical Garden of Mae Fah Luang University. Both P and B were cut into pieces with a length of approximately $10 \mathrm{~cm}$. After washing, it was dried in a hot air oven at $90^{\circ} \mathrm{C}$ for $1-2$ days, then pulverized and stored in a vacuum bag. The size or length of all particles obtained after pulverizing was in the range of $0.5-4 \mathrm{~cm}$.

\section{Pulp preparation}

The pulping of $\mathrm{R}, \mathrm{P}$ and $\mathrm{B}$ pulps were processed via the soda-AQ pulping process, and the procedure was summarized in Fig. 1. The pulping condition with $7 \% \mathrm{w} / \mathrm{w} \mathrm{NaOH}$ solution and cooking time for 30 min was used for R and B pulp preparation. The P pulp was obtained, however, by pulped with $4 \% \mathrm{w} / \mathrm{w} \mathrm{NaOH}$ solution and cooking time for $15 \mathrm{~min}$. Liquid to raw material ratio of 10:1 with the addition of $0.1 \% \mathrm{AQ}$ (based on the dried weight of raw materials) was used, and the cooking temperature was controlled at $98 \pm 2{ }^{\circ} \mathrm{C}$ for all batches. After cooking, the pulp was washed with tap water to rinse off the black liquor. The obtained pulp or unscreened (u-) was then screened through a metal mesh no. 18 and 200. The remaining pulp on mesh no. 200 was collected as a screened pulp (s-) portion. Then, the pulp slurries from both uand s- portions of R, P, and B pulps were prepared for further use in the molded pulp forming step.
Fig. 2 Preparation of molded pulp sheets from rice straw, pineapple leaf and banana stem pulps by using compression molding technique.

\section{Preparation of molded pulp sheets}

The procedure for sheet preparation followed the steps in Fig. 2. The pulp slurry was firstly preformed into rectangular shape. Then it was partially dewatered by a hydraulic pressing machine (M.S. Industry Supplied Co., LTD) under pressure of 0.6 MPa for 5 min [14]. After that, it was hot-pressed to form a molded sheet by using compression molding under pressure of $0.6 \mathrm{MPa}$ for $5 \mathrm{~min}$ at $130{ }^{\circ} \mathrm{C}$. All sample sheets were prepared with the same procedure.

\section{Sheet density determination}

All sample sheets were measured for their thickness randomly at 10 locations for an average value using a digital Vernier caliper, then pre-conditioned at $50 \% \mathrm{RH}, 25^{\circ} \mathrm{C}$, for at least $24 \mathrm{~h}$ before weighing. The density was calculated by the sheet weight divided by volume of sheet sample.

\section{Sheet morphology}

The surface and cross-section of the molded sheets were observed by scanning electron microscopy (SEM, LEO/1450 VP) at an accelerating voltage of $10 \mathrm{kV}$. All samples were cut into small pieces and then coated with gold by sputtering.

\section{Tensile testing}

The test specimens were cut from the sheets into the size of $80 \mathrm{~mm} \times 15 \mathrm{~mm}$ with a gauge length of $50 \mathrm{~mm}$. The specimens were pre-conditioned at $50 \% \mathrm{RH}, 25^{\circ} \mathrm{C}$ at least $24 \mathrm{~h}$ before testing, according to TAPPI T402. The tensile test followed the procedure of TAPPI T494 by using a universal testing machine (Instron Model 5566) with $1 \mathrm{kN}$ load cell. The test was performed at a constant crosshead speed of $7 \mathrm{~mm} / \mathrm{min}$. After testing, the tensile index, tensile strength, and elongation of the prepared molded sheets were evaluated. The 


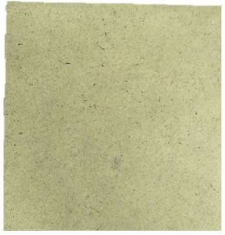

u-R sheet

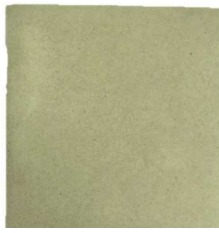

s-R sheet

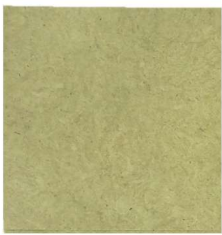

u-P sheet

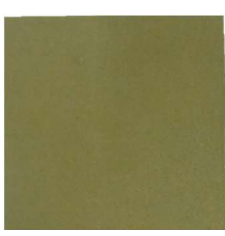

s-P sheet

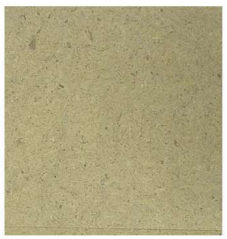

u-B sheet

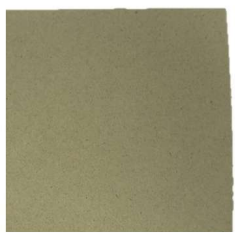

s-B sheet
Fig. 3 Molded sheets from unscreened and screened pulp from rice straw $(\mathrm{R})$, pineapple leaf $(\mathrm{P})$ and banana stem (B) pulps.

Table 1 Tensile properties of the molded sheets from unscreened and screened pulp of rice straw, pineapple leaf and banana stem pulps.

\begin{tabular}{lccc}
\hline Sample & $\begin{array}{c}\text { Tensile strength } \\
(\mathrm{MPa})\end{array}$ & $\begin{array}{c}\text { Elongation } \\
(\%)\end{array}$ & $\begin{array}{c}\text { Tensile index } \\
(\mathrm{Nm} / \mathrm{g})\end{array}$ \\
\hline $\mathrm{u}-\mathrm{R}$ & $57.90 \pm 5.69$ & $2.18 \pm 0.22$ & $60.49 \pm 4.48$ \\
$\mathrm{u}-\mathrm{P}$ & $57.16 \pm 3.27$ & $2.73 \pm 0.38$ & $56.06 \pm 1.95$ \\
$\mathrm{u}-\mathrm{B}$ & $37.25 \pm 3.63$ & $1.51 \pm 0.14$ & $44.19 \pm 2.49$ \\
\hline $\mathrm{s}-\mathrm{R}$ & $62.01 \pm 4.02$ & $3.67 \pm 0.76$ & $63.28 \pm 2.27$ \\
s-P & $45.10 \pm 5.66$ & $2.20 \pm 0.70$ & $43.71 \pm 4.17$ \\
s-B & $34.60 \pm 4.16$ & $2.45 \pm 0.46$ & $38.93 \pm 2.13$ \\
\hline
\end{tabular}

reported values of their tensile properties were averaged from 10 specimens.

\section{RESULTS}

\section{Molded sheet morphology}

The appearance of all prepared molded sheets is shown in Fig. 3. The molded sheet color varied depending on the initial color of their pulp sources. The $\mathrm{u}-\mathrm{R}, \mathrm{u}-\mathrm{P}$ and $\mathrm{u}-\mathrm{B}$ codes represented the molded sheets from unscreened pulp of rice straw, pineapple leaf and banana stem, respectively. The various fiber sizes dispersed in these sheets from unscreened pulps could be observed by the naked eye. The surfaces of $\mathrm{u}-\mathrm{R}, \mathrm{u}-\mathrm{P}$ and $\mathrm{u}-\mathrm{B}$ sheets were rougher while the surfaces of $s-R, s-P$ and $s-B$ (screened pulp) sheets were smoother. The grammage of unscreened molded sheet was approximately $240 \pm 28 \mathrm{~g} / \mathrm{m}^{2}$ and screened pulp sheet was $256 \pm 40 \mathrm{~g} / \mathrm{m}^{2}$. From SEM images (Fig. 4), all sheet surfaces showed that different size fibers were randomly entangled. The average diameters of $\mathrm{R}$, $\mathrm{P}$ and B fibers were $5.72 \pm 1.66 \mu \mathrm{m}, 5.13 \pm 1.70 \mu \mathrm{m}$ nd $17.46 \pm 5.77 \mu \mathrm{m}$, respectively. Long fibers on the surfaces of u-sheets were clearly seen whereas the ssheets showed less long fibers on their surfaces. For the observation on their cross-sections, the u- and ssheets from $\mathrm{R}$ and $\mathrm{P}$ pulps looked more similar and denser (Fig. 5) than those from the B pulp. Gaps or spaces between fiber layers were obviously observed in both $\mathrm{u}-\mathrm{B}$ and s-B sheets.

\section{Tensile properties}

The tensile properties of all samples were summarized in Table 1 . The $R$ sheets had the highest tensile strength and tensile index, followed by the $\mathrm{P}$ and $B$ sheets. The elongation of all sheets was in the range of $1.5-3.7 \%$. The s-sheets of $R$ and $B$ pulps showed no significant difference from their $\mathrm{u}$-sheets in the tensile properties. On the other hand, the tensile strength and index of the s-P sheet were visibly lower than those of the u-P sheet (Fig. 6). In comparison with other commercial molded pulp products, both $\mathrm{u}-\mathrm{R}$ and $\mathrm{s}-\mathrm{R}$ sheets showed higher tensile indices than the non-wood molded pulp and being close to the wood molded pulp properties. Besides, the tensile index of $\mathrm{u}-\mathrm{P}, \mathrm{s}-\mathrm{P}, \mathrm{u}-\mathrm{B}$ and $\mathrm{s}-\mathrm{B}$ sheets was also above or near that of the commercial non-wood molded pulp.

\section{DISCUSSION}

\section{Properties of molded sheets from different pulp types}

As shown in Fig. 4, the characteristic of R, P and $B$ fibers was slightly different. The surfaces of $u-$ $\mathrm{R}$ and $\mathrm{u}-\mathrm{P}$ sheets (Fig. $4 \mathrm{ab}$ ) presented smaller size fibers than those found on the u-B sheet (Fig. 4c). The density of all $\mathrm{R}$ and $\mathrm{P}$ sheets was close and in the range of $0.96-1.02 \mathrm{~g} / \mathrm{cm}^{3}$ (data in Fig. 5). But the density of B sheets was slightly lower (0.87$0.88 \mathrm{~g} / \mathrm{cm}^{3}$ ). Possibly, with smaller size fibers, both $\mathrm{R}$ and $\mathrm{P}$ pulps could better pack together and became closer leading to an increase in their sheet densities as compared to the B pulp sheets. In line with the cross-sections of $\mathrm{R}$ and $\mathrm{P}$ sheets (Fig. 5), the SEM images also showed less voids or gaps between the fiber layers compared to the B sheets. These gaps indicated poor fiber-fiber bonding within the B sheet structures and supposedly led to their lowest tensile properties (Table 1). Another reason that the $\mathrm{R}$ and $\mathrm{P}$ pulps gave higher sheet properties than the $B$ pulp was also that the thinner $R$ 

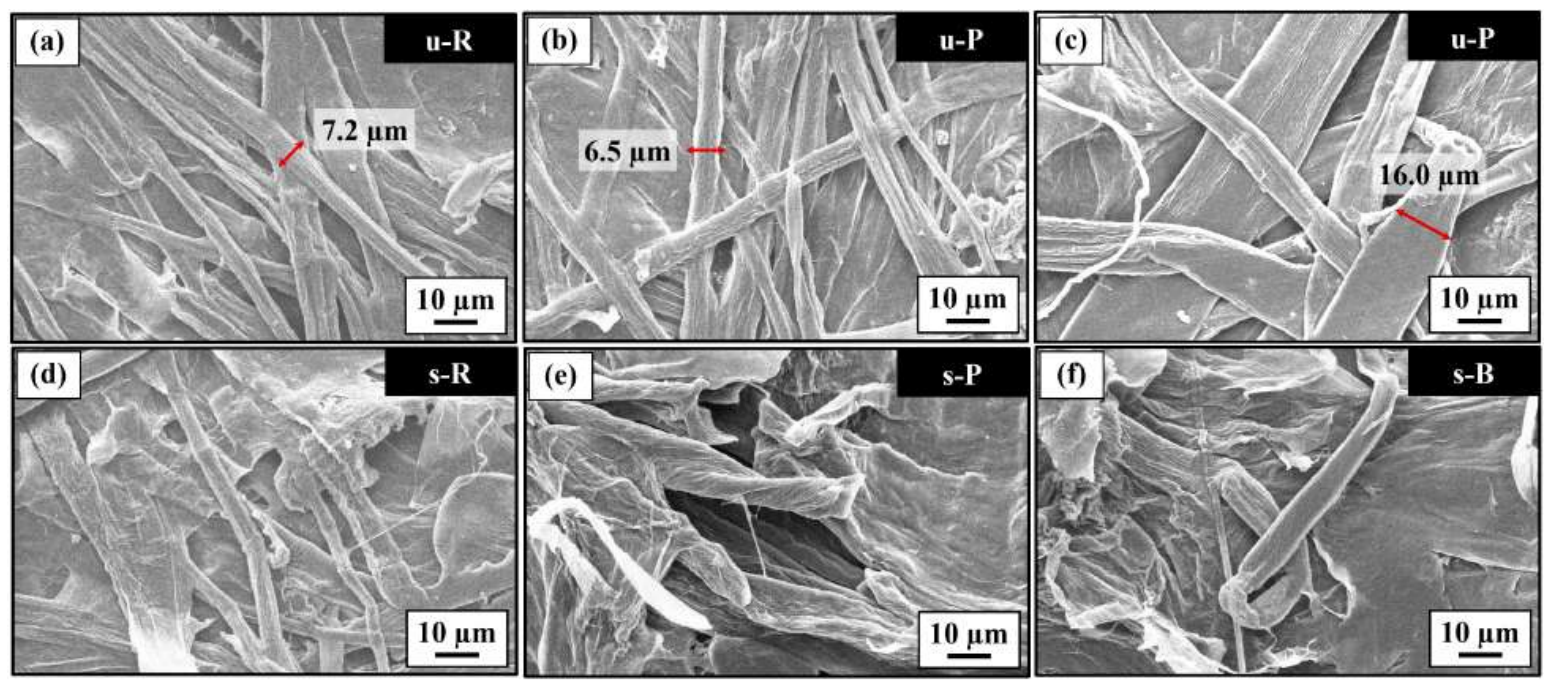

Fig. 4 SEM images of R, P and B molded sheet surfaces prepared from unscreened pulp (a)-(c) and screened pulp (d)-(f) (observed at $1000 \times$ magnification).

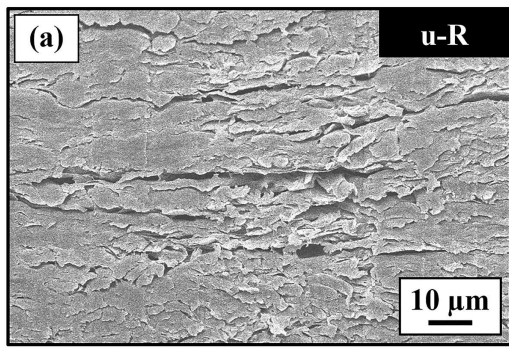

Density : $0.96 \pm 0.03 \mathrm{~g} / \mathrm{cm}^{3}$

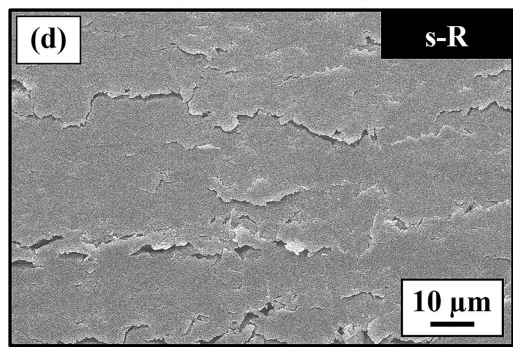

Density : $1.01 \pm 0.02 \mathrm{~g} / \mathrm{cm}^{3}$

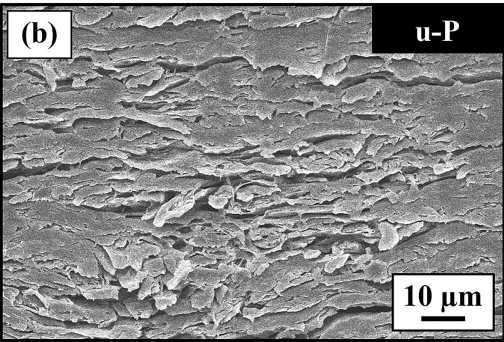

Density : $1.01 \pm 0.01 \mathrm{~g} / \mathrm{cm}^{3}$

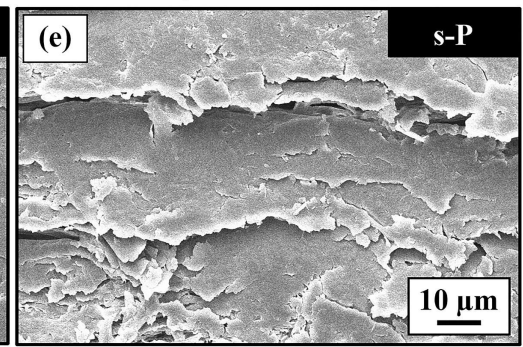

Density : $1.02 \pm 0.05 \mathrm{~g} / \mathrm{cm}^{3}$

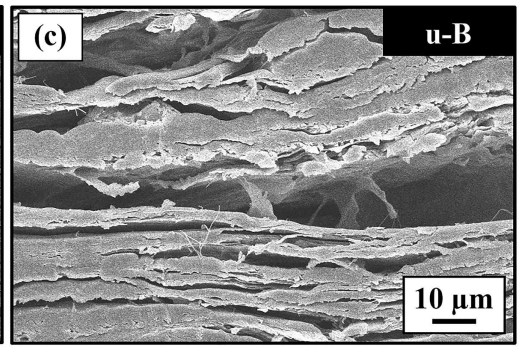

Density : $0.87 \pm 0.01 \mathrm{~g} / \mathrm{cm}^{3}$

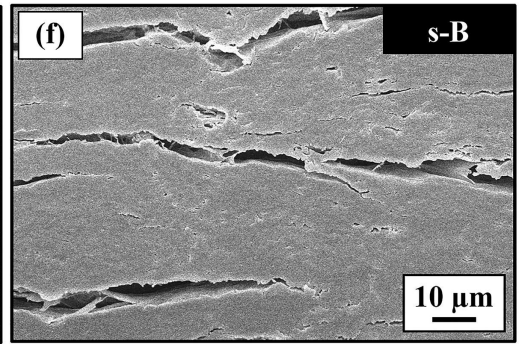

Density : $0.88 \pm 0.02 \mathrm{~g} / \mathrm{cm}^{3}$

Fig. 5 SEM images of cross-section areas of the sheets prepared from unscreened pulp (a)-(c) and screened pulp (d)-(f) (observed at $1000 \times$ magnification).

and $\mathrm{P}$ fibers with higher slenderness ratio (fiber length/width) provided a higher surface area for fiber-fiber bonding $[15,16]$. For $\mathrm{R}$ pulp, both $\mathrm{u}-\mathrm{R}$ and s-R sheets showed higher tensile strength and tensile index than the $\mathrm{P}$ and $\mathrm{B}$ sheets. The tensile indices of $\mathrm{R}$ sheets in this work were also higher or similar to those of the paper sheets from rice straw pulp (alkaline pulping) previously prepared by Jani et al [17] with the reported tensile index of $67.28 \mathrm{Nm} / \mathrm{g}$. These $\mathrm{R}$ sheets also showed higher tensile indices when compared to those of the rice straw paper sheet prepared from a soda-AQ process $(38.0-57.6 \mathrm{Nm} / \mathrm{g})$ in the work of Shao et al [18]. Furthermore, the tensile indices of the present $\mathrm{P}$ sheets were also comparable to the values reported in the previous work of Wutisatwongkul et al [19]. They prepared the handsheets from pineapple leaf pulp by a soda pulping process, having the tensile index of around $35.0-46.6 \mathrm{Nm} / \mathrm{g}$. Although without bleaching, the B sheets in this study already had 

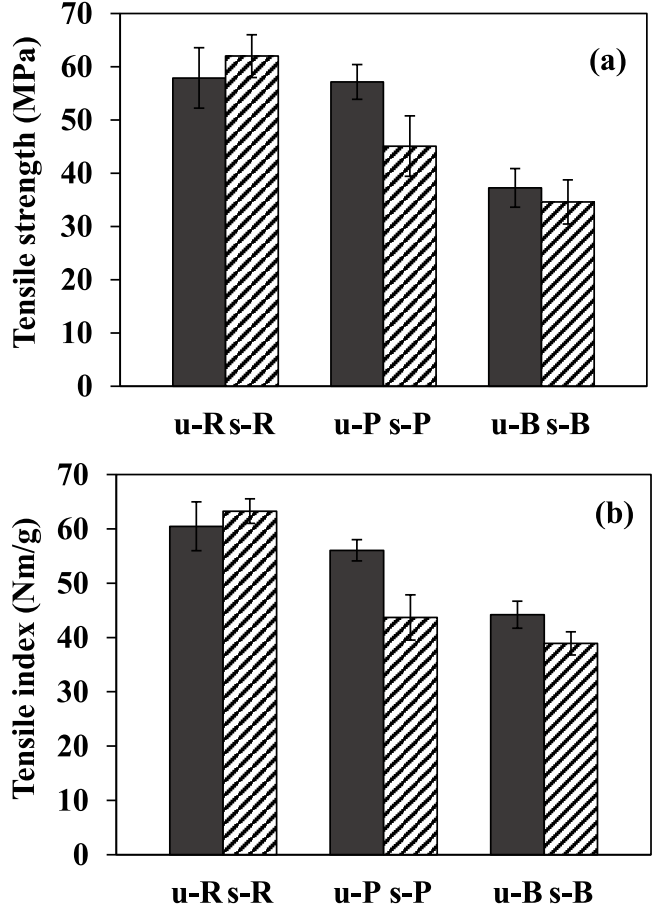

Fig. 6 (a) Tensile strength and (b) tensile index of unscreened pulp sheets compared with screened pulp sheets from R, P and B pulps.

the tensile properties close to the sheets from semibleached banana sheath pulp $(47.8-52.0 \mathrm{Nm} / \mathrm{g})$ in the previous research of Goswami et al [20].

\section{Effect of unscreened (u-) and screened (s-) pulps on sheet properties}

Fig. 4 showed the SEM images of the surfaces of all s- and u-sheets from R, P and B pulps. Random fiber arrangement and entanglement were observed. However, on the surfaces of the s-P and s-B sheets, long fibers which could create more fiberfiber interaction were hardly presented when compared to their u-sheets. This might be the reason why these s-P and s-B sheets showed lower tensile properties than the u-sheets. On the other hand, some long fibers were observed on both s-R and $\mathrm{u}-\mathrm{R}$ sheet surfaces (Fig. 4ad). The tensile strength and tensile index of the s-R and $\mathrm{u}-\mathrm{R}$ sheets were also found to be not significantly different (Fig. 6).

Molded pulps from R, $\mathrm{P}$ and $\mathrm{B}$ pulps versus commercial molded pulp products

From Fig. 7, the $\mathrm{u}-\mathrm{R}$ and s- $\mathrm{R}$ sheets exhibited higher tensile indices than the commercial nonwood molded pulp and were comparable to the wood molded pulp product. Therefore, the R pulp

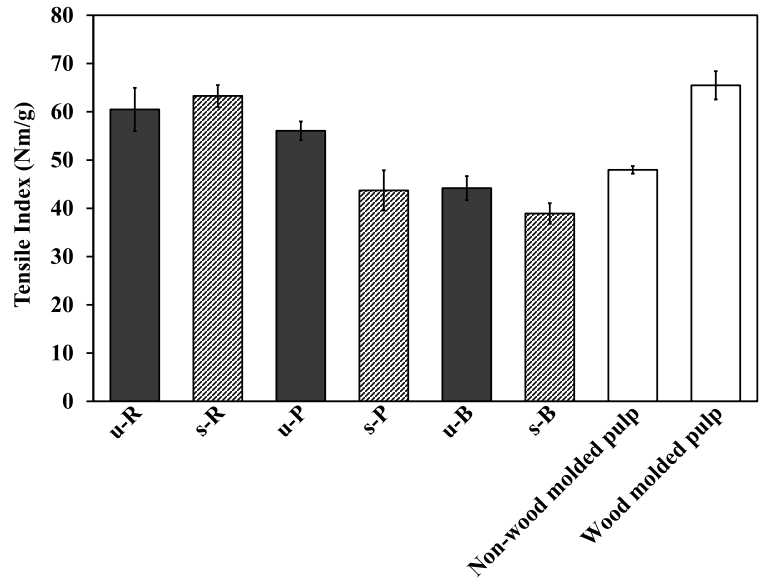

Fig. 7 Tensile index of all prepared molded pulp sheets in this work compared to the commercial molded pulp products from non-wood and wood pulps.

is very promising to use alternatively to both nonwood and wood pulps. In case of the $\mathrm{P}$ and $\mathrm{B}$ molded sheets, it is suggested that both pulps could be considered alternative non-wood pulp resources for molded pulp packaging.

\section{CONCLUSION}

The molded pulp sheets from rice straw (R), pineapple leaf $(\mathrm{P})$ and banana stem (B) were successfully prepared. The $\mathrm{R}$ and $\mathrm{B}$ molded sheets from unscreened (u-) and screened (s-) pulps showed only a slight difference in their tensile properties except for the P molded sheets. The $\mathrm{u}-\mathrm{R}$ and $\mathrm{s}-\mathrm{R}$ sheets showed the highest tensile strength of 57.90 and $62.01 \mathrm{MPa}$, respectively, and tensile index of 60.49 and $63.28 \mathrm{Nm} / \mathrm{g}$, respectively. These values were well above those of the commercial non-wood molded pulp product and as good as the commercial wood molded pulp product. With the tensile performance of the current molded sheets considered, the results indicated that all R, P, and B pulps had good potential for utilizing as raw materials in the molded pulp manufacturing.

Acknowledgements: The authors would like to thank Center of Innovative Materials for Sustainability (iMatS) and Scientific and Technological Instruments Center (STIC), Mae Fah Luang University (MFU) for financial support and the facilities. We also thank the Botanical Garden of Mae Fah Luang University for providing the B raw material. 


\section{REFERENCES}

1. Gurav SP, Bereznitski A, Heidweiller A, Kandachar PV (2003) Mechanical properties of paper-pulp packaging. Compos Sci Technol 63, 1325-1334.

2. Iqbal HMN, Kyazze G, Keshavarz T (2013) Advances in the valorization of lignocellulosic materials by biotechnology: an overview. BioResources $\mathbf{8}$, 3157-3176.

3. Chen C, Duan C, Li J, Liu Y, Ma X, Zheng L, Stavik J, Ni Y (2016) Cellulose (dissolving pulp) manufacturing processes and properties: A mini-review. BioResources 11, 5553-5564.

4. Lwako MKO, Byaruhanga JK, Baptist KJ (2013) A review on pulp manufacture from non wood plant materials. Int J Chem Eng Appl 4, 144-148.

5. Mukhopadhyay S, Fangueiro R, Arpac Y, Şentürk Ü (2008) Banana fibers-variability and fracture behaviour. J Eng Fiber Fabr 3, 39-45.

6. Yusof Y, Yahya SA, Adam A (2015) Novel technology for sustainable pineapple leaf fibers productions. Procedia CIRP 26, 756-760.

7. Laftah WA, Wan Abdul Rahman WA (2016) Pulping process and the potential of using non-wood pineapple leaves fiber for pulp and paper production: A review. J Nat Fibers 13, 85-102.

8. Dungani R, Karina M, Subyakto AS, Hermawan D, Hadiyane A (2016) Agricultural waste fibers towards sustainability and advanced utilization: A review. Asian J Plant Sci 15, 42-55.

9. Saijonkari-Pahkala K (2001) Non-wood plants as raw material for pulp and paper. Agric Food Sci 10S, 1-101.

10. Sridach W (2010) The environmentally benign pulping process of non-wood fibers. Suranaree J Sci Technol 17, 105-123.

11. Rudi H, Kermanian H, Resalati H, Rodi LT (2016) The effect of hot-water pre-extraction on the properties of soda-AQ pulp of wheat straw. Lignocellulose 5, 66-76.

12. Shakhes J, Zeinaly F, Marandi MA, Saghafi T (2011) The effects of processing variables on the soda and soda-aq pulping of kenaf bast fiber. BioResources 6 , 4626-4639.

13. Ates S, Deniz I, Kirci H, Atik C, Okan OT (2015) Comparison of pulping and bleaching behaviors of some agricultural residues. Turk J Agric For 39, 144-153.

14. Streitlien H (2015) Compression moulding of cellulose composites. MSc thesis, Chalmers Univ of Technology, Sweden.

15. Ogunjobi KM, Adetogun AC, Shofidiya SA (2014) Investigation of pulping potentials of waste from conversion of Anogeissus leiocarpus. IOSR J Polymer Text Eng 1, 26-30.

16. Akpabio UD, Akpakpan AE (2012) Pulp and paper from agricultural wastes: plantain pseudostem wastes and Screw pine leaves. Int J Mod Chem 2, 100-107.

17. Mohamad Jani S, Rushdan I (2016) Mechanical properties of beating pulp and paper from rice straw. $J$ Trop Agric And Fd Sc 44, 103-109.

18. Shao S, Wu C, Chen K (2017) Refining, dewatering, and paper properties of soda-anthraquinone (soda/AQ) pulp from rice straw. BioResources 12, 4867-4880.

19. Wutisatwongkul J, Thavarungkul N, Tiansuwan J, Termsuksawad P (2016) Influence of soda pulping variables on properties of pineapple (Ananas comosus Merr.) leaf pulp and paper studied by face-centered composite experimental design. Adv Mater Sci Eng 2016, ID 8915362.

20. Goswami T, Kalita D, Rao PG (2008) Greaseproof paper from banana (Musa paradisica L.) pulp fibre. Indian J Chem Technol 15, 457-461. 